\title{
Association of Life Course Socioeconomic Status and Adult Height With Cognitive Capacity Among Older Adults in India and China: A Cross-Sectional Study
}

Y Selvamani ( $\nabla$ selvinsw@gmail.com )

International Institute for Population Sciences https://orcid.org/0000-0002-1190-9127

P Arokiasamy

International Institute for Population Sciences

Research article

Keywords: Life-course, socioeconomic status, Height, Cognition, WHO-SAGE, Ageing

Posted Date: September 24th, 2020

DOl: https://doi.org/10.21203/rs.3.rs-72247/v1

License: (c) (1) This work is licensed under a Creative Commons Attribution 4.0 International License.

Read Full License 


\section{Abstract}

\section{Background}

Cognitive ability is an important measure of intrinsic capacity. In this study, we examine the association of life course socioeconomic status (SES) and height on cognitive functioning among older adults aged 50 and above for the two middle-income countries of India and China. We further assess the age pattern of cognitive decline with measures of life course socioeconomic status.

\section{Methods}

Cross-sectional comparative analysis was conducted using the WHO's Study on global AGEing and adult health (SAGE) data for India and China. Multilevel mixed-effect regression analysis was used to predict the association of life course socioeconomic status, height with cognitive functioning.

\section{Results}

In India and China, better childhood socioeconomic status measured as parental education is positively associated with cognitive functioning. The association between adult socioeconomic status and cognitive functioning was positive and highly significant. Height was significantly associated with improved cognitive functioning for India and China. Furthermore, the age-related cognitive decline was faster among older adults whose parents had no schooling, particularly the association between mother's education and cognitive functioning is stronger in China. The cognitive decline is much faster among less-educated older adults than those with 10+ years of schooling in China. Wealthier older adults in India had higher cognitive functioning in middle age, however, wealth differences narrowed in older ages, suggesting the convergence of cognitive functioning by economic status at older ages.

\section{Conclusions}

The results of this study suggest a significant long-term impact of childhood conditions on later-life cognitive functioning in middle-income settings.

\section{Background}

The age-associated change in mental health conditions such as cognitive impairment, depression and dementia are significant contributors to disease burden across the globe (1-3). Individuals who maintain better cognitive functioning in early years and old age have better outcomes such as improved quality of life, and lower risk of disabilities and all-cause of mortality (4-8).

While cognitive ability is an important measure of intrinsic capacity (9), evidence suggests that the level of cognitive ability differs across nations (10) and socioeconomic position $(11,12)$. Particularly, education is closely linked with better cognitive functioning and contributing to slower cognitive decline with age $(13,14)$ suggesting the role of cognitive reserve theory. In addition to individual-level factors 
such as nutrition, sleep problems, physical activity, food insecurity, oral health and social engagement are major determinants of cognitive functioning $(11,15-20)$. The contextual factors such as indoor and outdoor air pollution, living environment, green space, community-level socioeconomic status, economic recession at the time of birth, childhood and adulthood are also associated with cognitive functioning $(11,21-23)$.

Additionally, a growing body of literature suggests a significant role of early life conditions in determining health-related outcomes $(24,25)$ and cognitive functioning across the life course $(26)$. Childhood circumstance is one of the key factors in determining cognitive functioning across the life course and play important role in determining cross-national subgroup level variations $(27,28)$. Studies mainly from high-income countries showed a strong association of childhood circumstances such as poor socioeconomic status, and childhood poverty deprivation with cognitive functioning, cognitive impairment, and dementia $(24,29-35)$. Childhood socioeconomic status play an important role in determining higher educational attainment, immunisation, health and nutrition which has a significant impact in later life (36-39. Particularly, the association between the mother's educational attainment and cognitive functioning is strongly correlated independent of adult socioeconomic status (30). Parental education is a key and proxy measure of the intrinsic capacity of the family that is strongly correlated with several outcomes starting from childhood in improving living conditions and promoting capability (40). Lower parental education is associated with higher odds of cognitive impairment and dementia in later-life $(31,33)$. However, very few studies have examined the association between life course socioeconomic status and cognitive functioning in low and middle-income countries (41).

Furthermore, studies also examined the linkage between height and cognitive functioning. Adult height is a marker of net nutrition in early childhood (42-44). Many possible factors are responsible for variation in height across countries. They include population genetics, socioeconomic status, birth weight, maternal height and health and diseases environment (44-46). Childhood health and nutrition contribute significantly in determining the height of individual (45).

Previous literature has documented the health benefits of stature. Being tall, reflect in many ways on the individual outcome, on average taller people have a more economic advantage than short people; taller people earn more than their shorter counterparts $(47,48)$. Also, taller older adults have higher cognitive functioning than their shorter counterparts $(49,50)$ and are at lower risk of developing dementia (51-53). It is also notable that income-height relationship operates through higher cognitive abilities (47). Height is also associated with better health, happiness and overall quality of life (54-56). The cross-national variations in cognitive functioning are also partly explained by life course factors such as childhood nutrition reflected in height (10).

Childhood circumstances such as socioeconomic status and nutrition are important. Particularly, the impact of childhood circumstances will be larger in low and middle-income countries as childhood shocks are larger (57). However, very few studies have examined the association of life course socioeconomic status and height with cognition in middle-income countries (31). Moreover, not much is 
known about the life course socioeconomic status and cognitive functioning in India. It is also notable that the age-pattern of cognitive decline by life course socioeconomic status on cognitive functioning is less known in middle-income countries such as India and China. In this context, understanding the life course determinants of cognitive ability in India and China will be beneficial in the context of population ageing.

The rise in the share of the older population is rapid in India and China, the two most populated nations in the world with more than a third of the global population. With rapid demographic change such as the reduction in the fertility and improvement in health has resulted in the rise of life expectancy both in India and China. More specifically, the rise in life expectancy was faster in China than India and as a result, the share of the elderly population is rising rapidly (58). By 2050 , the share of elderly population (60+) is projected to reach 36.5 per cent in China and 19.4 per cent in India, respectively (59).

In this paper, we examine the association of early life circumstances such as childhood socioeconomic status (parental education and employment), adult height and adult socioeconomic status (years of schooling and wealth quintile) with cognitive functioning among older adults in two middle-income countries using WHO-SAGE data. We also examine the age pattern of cognitive decline by measures of life course socioeconomic position.

\section{Methods}

\section{Data and sample}

\section{WHO Study on global AGEing and adult health (SAGE)}

In this paper, data from the WHO's SAGE survey, a nationally representative household health survey conducted in six low and middle-income countries: China, Ghana, India, Mexico, the Russian Federation and South Africa during 2007-10 are used. SAGE data was collected by the World Health Organisation (WHO) with support from national and international organisations. The main aim of the SAGE survey was to fulfil the data gaps and understand the health and wellbeing of the growing ageing population in six low and middle-income countries. SAGE measures are comparable with other studies from high-income countries such as the Health and Retirement Study (HRS), and the Survey of Health, Ageing and Retirement in Europe (SHARE). SAGE collected data on self-reported as well as biomarkers on different domains of health, wellbeing and anthropometric indicators. Height was measured by trained health investigators. In addition, SAGE also collected data of parental characteristics such as parental education and employment. This analysis was conducted on the sample of 19,666 older adults aged 50 years and above for India $(n=6,560)$ and China $(n=13,106)$. More detailed information on sampling, methodology and data are provided in Kowal et al. (2012) (60). The SAGE study was approved by the Ethics Review Committee (RPC146), World Health Organization, Geneva, Switzerland and the Institutional Review Board, International Institute of Population Sciences, Mumbai, India and the ethics review committee of the Chinese Canter for Disease Control and Prevention (China CDC) (Approval notice 200601). 


\section{Outcome variable}

\section{Cognitive functioning}

The SAGE survey has collected information on cognitive ability measures such as immediate and delayed verbal recall, verbal fluency, and forward and backward digit span. In the analysis, we generated a standardised cognitive index combining these variables covering three domains of cognition using principal components analysis and finally converted index score ranges from 0 to 100 higher scores represent higher cognitive functioning (19).

\section{Predictor variables}

\section{Childhood Socio-Economic Status (SES).}

SAGE collected data on parental education and work status/employer for mother and father. The parental education responses were captured in seven categories from no formal education to post-graduation. For the analysis, we categorized parental education into four categories: no formal education, less than primary, completed primary or secondary and completed higher secondary (HS) or above. Parental employment was recoded into four categories; not employed, self-employment, employed in the informal sector, employed in the private sector/public sector.

\section{Height}

In the SAGE survey, height was measured in centimeters using a stadiometer by trained health investigators. In the analysis, sex and country-specific height quintiles were generated to examine the association between height and cognitive functioning in India and China.

\section{Measures of adult SES}

In this study, educational attainment, wealth quintile and work status have been included as measures of adult socioeconomic status. Educational attainment was categorized as 'no formal education', 'less than primary', 'completed primary or secondary' and 'completed higher secondary (HS) or above'. Wealth quintile variable was generated from measures of household amenities and ownership of durable goods and categorised as 'poorest', 'poorer', 'middle', 'richer', and 'richest'. List of household wealth variables used to calculate the wealth quintile is provided in the supplementary Table 1. Work status of the study participants was categorised as 'not employed', 'self-employed', 'informal sector', and 'private sector/public sector'.

\section{Demographic and health characteristics}

We included selected demographic and health variables as covariates which include are age (years), place of residence (urban/rural), marital status (currently married/otherwise), body mass index 
(underweight $\left(<18.5 \mathrm{~kg} / \mathrm{m}^{2}\right)$, normal $\left(18.5-24.9 \mathrm{~kg} / \mathrm{m}^{2}\right)$, overweight $\left(25.0-29.9 \mathrm{~kg} / \mathrm{m}^{2}\right)$, and obesity $\left.\left(30.0+\mathrm{kg} / \mathrm{m}^{2}\right)\right)$, poor self-rated health (SRH) (no/yes).

Activities of Daily Living (1+ADL) Limitations. data on list of the questions measuring difficulties in doing activities in the last 30 days has been used to generate the 1+ADL limitations variable. These questions captured difficulties in 'sitting for long periods', 'walking 100 meters', 'standing up from sitting down', 'standing for long periods', 'climbing one flight of stairs without resting', 'stooping/kneeling/crouching', 'picking up things with fingers', 'extending arms above shoulders', 'concentrating for 10 min', 'walking a long distance ( $1 \mathrm{~km})$ ', 'bathing, getting dressed', 'carrying things', 'moving around inside home', 'getting up from lying down', and 'getting to and using the toilet'. We recoded severe and extreme difficulties to represent the difficulties in activities of daily living. Further, we sum these measures into one variable and coded " 0 " as no difficulty" else (one or more) into " 1 " to represent $1+$ ADL limitations.

Sleep problems: In the SAGE survey, the prevalence of sleep problems was evaluated with the following question 'Overall in the last 30 days, how much of a problem did you have with sleeping, such as falling asleep, waking up frequently during the night or waking up too early in the morning?' response categories were none, mild, moderate, severe, extreme/cannot do. Those who reported 'severe' and 'extreme/cannot do' were considered as having sleeping problems.

Edentulism (Loss of all natural teeth): The prevalence of complete tooth loss was assessed with the following question. 'Have you lost all of your natural teeth?' Those who said yes were coded as 1 "edentulous" else into 0 "dentate'.

\section{Health behaviours}

Physically inactive: those who reported physical activity less than 300 minutes in a week are considered as physically inactive. Tobacco use was categorised as yes or no. Alcohol consumption was categorised as yes if the respondent consumed 1-4 days/week or more in the last 12 months' versus no.

\section{Statistical Analysis}

Bivariate analysis was used to understand the sample distribution by background characteristics. Further, we assessed the association of life course socioeconomic status and height (quintile) and cognitive functioning using multilevel mixed-effect regression models. We used three-level random intercept regression models which included province at the first level, Primacy Sampling Unit (PSU) at second and individual at the third level. Furthermore, to understand the age patterns of cognitive functioning trajectories by life course socioeconomic status, we used the interaction of life course socioeconomic status measures such as parental education and adult socioeconomic status (schooling and wealth quintile) and age. All analyses were carried out in STATA 15.0.

\section{Results}


Descriptive statistics of the study participants are provided in Table 1. The mean age of study participants was 61.5 years in India and 61.6 years in China. Overall cognition functioning score is higher in China where older adults in China had more than 10 points higher cognition score than the Indian counterparts. Older adults in China were slightly taller than their counterparts in India. The distribution of the sample by place of residence showed more than half of the sample were from rural areas in India and China. A large proportion of study participants in China were currently married (85.0\%) as compared to 77 per cent in India. In India, more than half of older adults had no formal education. About 27 per cent of older adults in India have never worked. In India and China, around 90 per cent of the participant's mother had no schooling. More than 65 per cent of the study participant's father had no schooling. In India, about 65 of the study participant's mother never worked, compared to 38.7 per cent in China. A higher

percentage of older adults in India reported sleep problems (14.5\%), compared to $2.7 \%$ in China. Similarly, the prevalence rate of loss of all natural teeth (edentulism) was higher in India and a large proportion of the study participants in India were underweight (38\%). The prevalence of poor self-rated health among study participants was 22.4 and 21.2 per cent in India and China, respectively. More than half of study participants in India have reported 1+ADL limitations. The prevalence of tobacco use was higher in India (47\%) and the prevalence of physical inactivity was higher in China.

\section{Results from Multivariate analysis}

Results from multilevel multivariate regression models showed that parental education was significantly and positively associated with late-life cognition in India and China (Table 2). The association between father's education and cognitive functioning is strong and positive. Older adults in India and China whose fathers completed high school (HS) or above had higher cognitive functioning score $(\beta=2.53, \mathrm{Cl}$ : $1.37,3.70, p<.001)$ and $(\beta=3.55, \mathrm{Cl}: 2.47,4.62, \mathrm{p}<.001)$ than of older adults whose fathers had no schooling, respectively. In India, the father's employment was positively associated with cognitive functioning. Further, height is strongly and positively associated with cognitive functioning score. Older adults in the highest height quintile category in India $(\beta=1.80, \mathrm{Cl}: 1.14,2.45, p<.001)$ and China $(\beta=2.23$, Cl: $1.60,2.86, p<.001)$ had a better cognitive functioning score, respectively. Educational attainment of the study participants and wealth quintile emerged as strong predictors of cognitive functioning. Age was negatively associated with cognitive functioning, this association was stronger for older adults in China. Furthermore, sleep problems and edentulism (loss of all natural teeth) were strongly associated with cognitive functioning. Being underweight was associated with lower cognitive functioning in India. Poor self-rated health was negatively associated with cognitive functioning in India $(\beta=-1.59, \mathrm{Cl}:-2.15,-1.02, p$ $<.001)$ and China $(\beta=-2.05, \mathrm{Cl}:-2.52,-1.58, p<.001)$. Similarly, the association between $1+A D L$ limitations and cognitive functioning was significant in India $(\beta=-1.02, \mathrm{Cl}:-1.48,-.57, \mathrm{p}<.001)$ and China $(\beta=-2.80, \mathrm{Cl}$ : $-3.41,-2.20, p<.001)$. Tobacco use and physically inactive was negatively associated with cognitive functioning in India. 
Fig. 1 shows the predicted cognitive functioning for India and China by parental education at different ages. We used the interaction between age and parental education to show the age pattern of decline in cognitive functioning. Across different ages, cognitive ability score is higher for older adults whose mother and father had high school and above education. Particularly, the age-associated decline in cognitive ability is lower for older adults in India and China whose mother had high school or above education. Similarly, the age-associated decline in cognitive ability is lower for older adults in China whose father had high school or above education.

Fig. 2 shows that age-associated decline in cognitive ability by educational attainment and wealth quintile. In India and China, older adults with 10+ years of schooling had higher cognitive abilities across different ages, more strongly in India. The cognitive decline is much faster among less-educated older adults than those with $10+$ years of schooling in China. Wealthier older adults in India had higher cognitive functioning in middle age, however, the wealth differences narrowed in older ages, suggesting the convergence of cognitive functioning by economic status at older ages.

\section{Discussion}

Research on the role of early-life conditions in determining later-life outcomes has not gained much attention in middle-income countries. This study assessed the relationship of life course socioeconomic status and height with cognitive functioning among the older adult population in two middle-income countries, India and China. We also examined the interaction of age and measures of life course socioeconomic status in determining cognitive functioning trajectories.

We found a significant and positive association between parental education and cognitive functioning of the study participants in India and China. Father's work status is significantly associated with cognitive functioning of the study participants in India. Furthermore, respondent's socioeconomic status measured as years of schooling and household economic status (wealth quintile) strongly predicted cognitive functioning. Furthermore, the age-associated cognitive decline is faster among older adults whose parents had no schooling. The pattern is clearer for parental education in China where the age-related cognitive decline is steeper among older adults whose mothers and fathers had no schooling. Height showed a significant and positive association with the cognitive functioning in India and China. Crossnational and gender differences in cognitive functioning were notable. Older adults in India had lower cognitive functioning score than their Chinese counterparts. Older women in India had lower cognitive functioning score than men counterparts. Poor self-rated health, sleep problems and edentulism were negatively associated with cognitive functioning.

The results of this study are consistent with previous studies conducted on the association between parental education and later life cognition suggesting the long-term effect of childhood circumstances in developing countries such as China and South Africa $(31,32,35,41)$. We also observed a faster decline of cognitive functioning among older adults whose parents had no schooling which highlighted the role of childhood circumstances across different age period as consistent with previous literature (61). 
Previous studies had shown a significant positive relationship between childhood socioeconomic status and cognitive functioning in old age $(30,32-34)$. A recent study based on SHARE data for European countries found a significant positive relationship between childhood socioeconomic status and cognitive functioning (29).

The association between participant's socioeconomic status and cognitive functioning is notable. In this study, educational attainment was a strong predictor of cognitive functioning as shown previously ( 13 , $14,20)$. This association is consistent across different age, suggesting the role of education in cognitive reserve. In China, the cognitive decline is slower among older adults with $10+$ years of schooling consistent with previous literature (61). The results suggested the role of education in determining cognitive reserve in old age (62). Low education is associated with higher risk of cognitive impairment and dementia (63). In this context, the role of education highlights as a protective factor of cognitive functioning across age. On the other hand, in India, wealthier older adults had higher cognitive functioning in early age, however, the wealth gradient narrowed in older ages. The results support the convergence of health hypothesis (64). The results are consistent with previous literature in the Indian context which suggested convergence of health economic inequality with age (65). In the health literature, health inequality tends to narrow in old age mainly as a result of mortality selection (64). In India, the measure of economic status measured using wealth quintile shows an important role as a protective factor of health status and access to nutrition. The results of the present study suggest a significant role of economic status, specifically in the early age of 50-64.

In this study, height was significantly associated with higher cognitive functioning. The results are similar to previous studies from high and middle-income countries $(17,32,50)$. The association of height with health-related outcomes suggest a long-lasting relationship of childhood circumstances with later life outcomes. In particular, this association is stronger in low and middle-income settings which supports the hypothesis of a stronger effect of childhood circumstances in low-income settings $(44,57)$.

Poor self-rated health and 1+ADL were negatively associated with cognitive functioning which suggested the significant role of general health and functional limitations in old age. The association between poor self-rated health and cognitive functioning is consistent with previous studies (66). Poor self-rated health is a well-known indicator of general health which is a strong predictor of mortality (67). The association between $1+A D L$ and cognition was significant as shown in previous studies (68). Oral health condition measured as loss of all natural teeth was negatively associated with cognition (16).

The results of this study highlighted the significance of early life conditions in the low and middle-income setting. Poor socioeconomic status across the life course continues to affect the individual outcomes on various health measures such as handgrip strength (69), frailty (70), and respiratory function (71). Studies showed that childhood socioeconomic status plays an important role in access to nutrition, health, and education which further affect the various individual outcomes throughout the life course (24, 47). Especially, parental education has a significant role; educated parents are more likely to escape from the adverse environmental circumstances during pregnancy and better placed in providing better 
nurturing $(72)$ and immunisation for their children $(38,39)$. Childhood health and nutrition play as a human capital measure have long-lasting impact on health and wellbeing of their children. Also, they support their children to escape from violence and multiple risk factors through having better environmental circumstance with less violence. Children in poor childhood circumstance experience more health risk behaviour such as smoking and poor dietary habits (73). Therefore, the role of better childhood circumstances is important in determining health and wellbeing across the life course.

\section{Strengths and Limitations}

This study has used measured height data to examine the relationship between height and cognitive functioning. While most of the previous studies have used self-reported height $(47,50)$, in this study, we used two important childhood measures; height as a measure of childhood health and net-nutrition and childhood socioeconomic status. Previous studies have focussed on either childhood socioeconomic status or height.

The limitations of the study are; the results of this study are based on cross-sectional data. Previous literature has observed age-related decline in height $(74,75)$. The age-associated decline in height is not accounted for in the analysis. Jain and $\mathrm{Ma}$ (2020) (75) showed that height shrinkage is associated with lower cognition and health-related outcomes among the elderly. Furthermore, we relied on a few selected measures of childhood socioeconomic status, while several studies have used multiple measures of childhood socioeconomic status. Furthermore, the childhood socioeconomic status was assessed through the retrospective questions in the survey where there is a chance of misreporting. Moreover, in SAGE survey, the measures of childhood health ware not adequately collected unlike other surveys from high-income countries such as Health and Retirement Study (HRS) and Survey of Health, Ageing and Retirement in Europe (SHARE).

\section{Conclusion}

The results of this study suggest that childhood socioeconomic circumstances and adult height as a proxy measure of childhood nutrition play an important role in determining later-life cognition independent of adult socioeconomic status, demographic and health risk factors. In India and China, parental education was significantly associated with cognitive functioning. The age-associated decline in cognitive functioning is slower among older adults in China whose parents have completed high school or above. Years of schooling and household economic status were significant factors in determining cognitive functioning among older adults in India and China. Results highlight the role of parental education and own education across the life course in determining and maintaining better cognitive functioning. The role of wealth quintile in determining cognitive ability is stronger in middle age to late middle age. Height is an important early life marker in determining the cognitive functioning in later life suggesting the strong association of childhood nutrition and health. The findings of this study suggest improving health and nutrition in early childhood tend to have a long-lasting impact on cognitive functioning. 


\section{Abbreviations}

SES: Socio-Economic Status; WHO-SAGE: World Health Organisation Study on global AGEing and adult health; HRS: Health and Retirement Study; SHARE: Survey of Health, Ageing and Retirement in Europe; SRH: Self-Rated Health; ADL: Activities of Daily Living; PSU: Primacy Sampling Unit

\section{Declarations}

\section{Ethics approval and consent to participate}

The SAGE study was approved by the Ethics Review Committee (RPC146), World Health Organization, Geneva, Switzerland and the Institutional Review Board, International Institute of Population Sciences, Mumbai, India and the ethics review committee of the Chinese Canter for Disease Control and Prevention (China CDC) (Approval notice 200601). Informed written consent was obtained from each participant, who were ensured that data would remain confidential and used for research purposes only.

\section{Consent for publication}

Not applicable.

\section{Availability of data and materials}

The data-sets used in the present study are available from the corresponding author on request.

Competing Interest: The authors declare that they have no competing interest

Funding: The authors received no specific funding for this work

\section{Author contributions}

Y.S designed and wrote the initial draft and performed analysis. P. A conceptualized the study and provided critical revisions in content, data analysis and interpretation, and manuscript revision. Y. S and P.A reviewed and approved the final version of the manuscript.

\section{Acknowledgements}

The authors thank the World Health Organization-Study on global AGEing and adult health (SAGE), for providing data access. SAGE survey was supported by the Division of Behavioral and Social Research, National Institute on Aging and the Department of Health Statistics and Information Systems, World Health Organization (Grant 1 R01 AG034479-01A1). We are also thankful to Dr. Pushpendra Singh for his help during preparation of the manuscript.

\section{References}


1. Ahmed R, Kesavayuth D, Zikos V. Does being smarter make you happier? Evidence from Europe. Journal of Behavioral and Experimental Economics. 2018 Oct 1;76:55-67.

2. Jokela M, Singh-Manoux A, Ferrie JE, Gimeno D, Akbaraly TN, Shipley MJ, Head J, Elovainio M, Marmot MG, Kivimäki M. The association of cognitive performance with mental health and physical functioning strengthens with age: the Whitehall II cohort study. Psychological medicine. 2010 May;40(5):837.

3. Shimada H, Makizako H, Doi T, Tsutsumimoto K, Lee S, Suzuki T. Cognitive impairment and disability in older Japanese adults. PLoS One. 2016 Jul 14;11(7):e0158720.

4. Batty GD, Deary IJ, Zaninotto P. Association of cognitive function with cause-specific mortality in middle and older age: follow-up of participants in the english longitudinal study of ageing. American journal of epidemiology. 2016 Feb 1;183(3):183-90.

5. Gottfredson LS, Deary IJ. Intelligence predicts health and longevity, but why?. Current Directions in Psychological Science. 2004 Feb;13(1):1-4.

6. McGuire LC, Ford ES, Ajani UA. The impact of cognitive functioning on mortality and the development of functional disability in older adults with diabetes: the second longitudinal study on aging. BMC geriatrics. 2006 Dec 1;6(1):8.

7. Singh P, Govil D, Kumar V, Kumar J. Cognitive impairment and quality of life among elderly in India. Applied Research in Quality of Life. 2017 Dec 1;12(4):963-79.

8. An J, Li H, Tang Z, Zheng D, Guo J, Liu Y, Feng W, Li X, Wang A, Liu X, Tao L. Cognitive Impairment and Risk of All-Cause and Cardiovascular Disease Mortality Over 20-Year Follow-up: Results From the BLSA. Journal of the American Heart Association. 2018 Aug 7;7(15):e008252.

9. Ramírez-Vélez R, Correa-Bautista JE, García-Hermoso A, Cano CA, Izquierdo M. Reference values for handgrip strength and their association with intrinsic capacity domains among older adults. Journal of cachexia, sarcopenia and muscle. 2019 Apr;10(2):278-86.

10. Skirbekk V, Loichinger $E$, Weber $D$. Variation in cognitive functioning as a refined approach to comparing aging across countries. Proceedings of the National Academy of Sciences. 2012 Jan 17;109(3):770-4.

11. Wu F, Guo Y, Zheng Y, Ma W, Kowal P, Chatterji S, Wang L. Social-economic status and cognitive performance among Chinese aged 50 years and older. PloS one. 2016 Nov 18;11(11):e0166986.

12. Yang L, Martikainen P, Silventoinen K, Konttinen H. Association of socioeconomic status and cognitive functioning change among elderly Chinese people. Age and ageing. 2016 Sep 1;45(5):67480.

13. Foverskov E, Glymour MM, Mortensen EL, Holm A, Lange T, Lund R. Education and cognitive aging: accounting for selection and confounding in linkage of data from the Danish registry and survey of health, ageing and retirement in Europe. American journal of epidemiology. $2018 \mathrm{Nov}$ 1;187(11):2423-30.

14. Clouston SA, Smith DM, Mukherjee S, Zhang Y, Hou W, Link BG, Richards M. Education and cognitive decline: An integrative analysis of global longitudinal studies of cognitive aging. The Journals of 
Gerontology: Series B. 2020 Aug 13;75(7):e151-60.

15. Ahrenfeldt LJ, Lindahl-Jacobsen R, Rizzi S, Thinggaard M, Christensen K, Vaupel JW. Comparison of cognitive and physical functioning of Europeans in 2004-05 and 2013. International journal of epidemiology. 2018 Oct 1;47(5):1518-28.

16. Li J, Xu H, Pan W, Wu B. Association between tooth loss and cognitive decline: a 13-year longitudinal study of Chinese older adults. PloS one. 2017 Feb 3;12(2):e0171404.

17. Kobayashi LC, Berkman LF, Wagner RG, Kahn K, Tollman S, Subramanian SV. Education modifies the relationship between height and cognitive function in a cross-sectional population-based study of older adults in rural South Africa. European journal of epidemiology. 2019 Feb;34(2):131-9.

18. Leist AK, Hessel P, Avendano M. Do economic recessions during early and mid-adulthood influence cognitive function in older age?. J Epidemiol Community Health. 2014 Feb 1;68(2):151-8.

19. Selvamani Y, Singh P. Socioeconomic patterns of underweight and its association with self-rated health, cognition and quality of life among older adults in India. PLoS One. $2018 \mathrm{Mar}$ 7;13(3):e0193979.

20. Yaffe K, Fiocco AJ, Lindquist K, Vittinghoff E, Simonsick EM, Newman AB, Satterfield S, Rosano C, Rubin SM, Ayonayon HN, Harris TB. Predictors of maintaining cognitive function in older adults: the Health ABC study. Neurology. 2009 Jun 9;72(23):2029-35.

21. Cherrie MP, Shortt NK, Mitchell RJ, Taylor AM, Redmond P, Thompson CW, Starr JM, Deary IJ, Pearce JR. Green space and cognitive ageing: A retrospective life course analysis in the Lothian Birth Cohort 1936. Social Science \& Medicine. 2018 Jan 1;196:56-65.

22. Krishnamoorthy Y, Sarveswaran G, Sivaranjini K, Sakthivel M, Majella MG, Kumar SG. Association between indoor air pollution and cognitive impairment among adults in rural Puducherry, South India. Journal of neurosciences in rural practice. 2018 Oct;9(4):529.

23. Salinas-Rodríguez A, Fernández-Niño JA, Manrique-Espinoza B, Moreno-Banda GL, Sosa-Ortiz AL, Qian ZM, Lin H. Exposure to ambient PM2. 5 concentrations and cognitive function among older Mexican adults. Environment international. 2018 Aug 1;117:1-9.

24. McEniry M. Early-life conditions and older adult health in low-and middle-income countries: a review. Journal of developmental origins of health and disease. 2013 Feb;4(1):10.

25. Pavela G, Latham K. Childhood conditions and multimorbidity among older adults. Journals of Gerontology Series B: Psychological Sciences and Social Sciences. 2016 Sep 1;71(5):889-901.

26. Richards M, Deary IJ. A life course approach to cognitive reserve: a model for cognitive aging and development?. Annals of Neurology: Official Journal of the American Neurological Association and the Child Neurology Society. 2005 Oct;58(4):617-22.

27. Fors $S$, Lennartsson C, Lundberg 0 . Childhood living conditions, socioeconomic position in adulthood, and cognition in later life: exploring the associations. Journals of Gerontology Series B: Psychological Sciences and Social Sciences. 2009 Nov 1;64(6):750-7.

28. Doblhammer G, Van den Berg GJ, Fritze T. Economic conditions at the time of birth and cognitive abilities late in life: evidence from ten European countries. PloS one. 2013 Sep 11;8(9):e74915. 
29. Aartsen MJ, Cheval B, Sieber S, Van der Linden BW, Gabriel R, Courvoisier DS, Guessous I, BurtonJeangros C, Blane D, Ihle A, Kliegel M. Advantaged socioeconomic conditions in childhood are associated with higher cognitive functioning but stronger cognitive decline in older age. Proceedings of the National Academy of Sciences. 2019 Mar 19;116(12):5478-86.

30. Kaplan GA, Turrell G, Lynch JW, Everson SA, Helkala EL, Salonen JT. Childhood socioeconomic position and cognitive function in adulthood. International journal of epidemiology. $2001 \mathrm{Apr}$ 1;30(2):256-63.

31. Luo Y, Waite LJ. The impact of childhood and adult SES on physical, mental, and cognitive wellbeing in later life. The Journals of Gerontology Series B: Psychological Sciences and Social Sciences. 2005 Mar 1;60(2):S93-101.

32. Kobayashi LC, Glymour MM, Kahn K, Payne CF, Wagner RG, Montana L, Mateen FJ, Tollman SM, Berkman LF. Childhood deprivation and later-life cognitive function in a population-based study of older rural South Africans. Social Science \& Medicine. 2017 Oct 1;190:20-8.

33. Rogers MA, Plassman BL, Kabeto M, Fisher GG, McArdle JJ, Llewellyn DJ, Potter GG, Langa KM. Parental education and late-life dementia in the United States. Journal of geriatric psychiatry and neurology. 2009 Mar;22(1):71-80.

34. Zhang Z, Liu J, Li L, Xu H. The long arm of childhood in China: early-life conditions and cognitive function among middle-aged and older adults. Journal of aging and health. 2018 Sep;30(8):1319-44.

35. Yang L, Wang Z. Early-Life Conditions and Cognitive Function in Middle-and Old-Aged Chinese Adults: A Longitudinal Study. International Journal of Environmental Research and Public Health. 2020 Jan;17(10):3451.

36. Vukojevic M, Zovko A, Talic I, Tanovic M, Resic B, Vrdoljak I, Splavski B. Parental Socioeconomic Status as a Predictor of Physical and Mental Health Outcomes in Children-Literature Review. Acta Clin Croat. 2017 Dec 1;56(4):742-8.

37. Currie J, Goodman J. Parental socioeconomic status, child health, and human capital. InThe Economics of Education 2020 Jan 1 (pp. 239-248). Academic Press.

38. Vikram K, Vanneman R, Desai S. Linkages between maternal education and childhood immunization in India. Social science \& medicine. 2012 Jul 1;75(2):331-9.

39. Vikram K, Vanneman R. Maternal education and the multidimensionality of child health outcomes in India. Journal of biosocial science. 2020 Jan;52(1):57.

40. Krishnakumar J, Ballon P. Estimating basic capabilities: A structural equation model applied to Bolivia. World Development. 2008 Jun 1;36(6):992-1010.

41. Sha T, Yan Y, Cheng W. Associations of childhood socioeconomic status with mid-life and late-life cognition in Chinese middle-aged and older population based on a 5-year period cohort study. International journal of geriatric psychiatry. 2018 Oct;33(10):1335-45.

42. Bozzoli C, Deaton A, Quintana-Domeque C. Adult height and childhood disease. Demography. 2009 Nov 1;46(4):647-69. 
43. Deaton A. Height, health, and development. Proceedings of the national academy of sciences. 2007 Aug 14;104(33):13232-7.

44. Perkins JM, Subramanian SV, Davey Smith G, Özaltin E. Adult height, nutrition, and population health. Nutrition reviews. 2016 Mar 1;74(3):149-65.

45. Silventoinen K. Determinants of variation in adult body height. Journal of biosocial science. 2003 Apr 1;35(2):263.

46. Wood AR, Esko T, Yang J, Vedantam S, Pers TH, Gustafsson S, Chu AY, Estrada K, Kutalik Z, Amin N, Buchkovich ML. Defining the role of common variation in the genomic and biological architecture of adult human height. Nature genetics. 2014 Nov;46(11):1173-86.

47. Case A, Paxson C. Stature and status: Height, ability, and labor market outcomes. Journal of political Economy. 2008 Jun;116(3):499-532.

48. Vogl TS. Height, skills, and labor market outcomes in Mexico. Journal of Development Economics. 2014 Mar 1;107:84-96.

49. Maurer J. Height, education and later-life cognition in Latin America and the Caribbean. Economics \& Human Biology. 2010 Jul 1;8(2):168-76.

50. Guven C, Lee WS. Height, aging and cognitive abilities across Europe. Economics \& Human Biology. 2015 Jan 1;16:16-29.

51. Beeri MS, Davidson M, Silverman JM, Noy S, Schmeidler J, Goldbourt U. Relationship between body height and dementia. The American journal of geriatric psychiatry. 2005 Feb 1;13(2):116-23.

52. Russ TC, Kivimäki M, Starr JM, Stamatakis E, Batty GD. Height in relation to dementia death: individual participant meta-analysis of $18 \mathrm{UK}$ prospective cohort studies. The British Journal of Psychiatry. 2014 Nov;205(5):348-54.

53. Jørgensen TS, Okholm GT, Christensen K, Sørensen TI, Osler M. Body height in young adult men and risk of dementia later in adult life. Elife. 2020 Feb 11;9:e51168.

54. Deaton A, Arora R. Life at the top: the benefits of height. Economics \& Human Biology. 2009 Jul 1;7(2):133-6.

55. McGovern ME. Comparing the relationship between stature and later life health in six low and middle income countries. The journal of the economics of ageing. 2014 Dec 1;4:128-48.

56. Sohn K. Height and happiness in a developing country. Journal of Happiness Studies. 2016 Feb 1;17(1):1-23.

57. Currie J, Vogl T. Early-life health and adult circumstance in developing countries. Annu. Rev. Econ.. 2013 Aug 2;5(1):1-36.

58. Singh GK, Liu J. Health improvements have been more rapid and widespread in China than in India: A comparative analysis of health and socioeconomic trends from 1960 to 2011. International journal of MCH and AIDS. 2012;1(1):31.

59. United Nations. Department of economic and social affairs, population division. world population prospects: The 2015 revision, key findings and advance tables. InTechnical Report: Working Paper 
No. ESA/P/WP. 2412015.

60. Kowal P, Chatterji S, Naidoo N, Biritwum R, Fan W, Lopez Ridaura R, Maximova T, Arokiasamy P, Phaswana-Mafuya N, Williams S, Snodgrass JJ. Data resource profile: the World Health Organization Study on global AGEing and adult health (SAGE). International journal of epidemiology. 2012 Dec 1;41(6):1639-49.

61. Zaninotto P, Batty GD, Allerhand M, Deary IJ. Cognitive function trajectories and their determinants in older people: 8 years of follow-up in the English Longitudinal Study of Ageing. J Epidemiol Community Health. 2018 Aug 1;72(8):685-94.

62. Farfel JM, Nitrini R, Suemoto CK, Grinberg LT, Ferretti RE, Leite RE, Tampellini E, Lima L, Farias DS, Neves RC, Rodriguez RD. Very low levels of education and cognitive reserve: a clinicopathologic study. Neurology. 2013 Aug 13;81(7):650-7.

63. Prince M, Acosta D, Ferri CP, Guerra M, Huang Y, Rodriguez JJ, Salas A, Sosa AL, Williams JD, Dewey ME, Acosta I. Dementia incidence and mortality in middle-income countries, and associations with indicators of cognitive reserve: a 10/66 Dementia Research Group population-based cohort study. The Lancet. 2012 Jul 7;380(9836):50-8.

64. Beckett M. Converging health inequalities in later life-an artifact of mortality selection?. Journal of health and social behavior. 2000 Mar 1:106-19.

65. Arokiasamy P, Selvamani Y. Age, socioeconomic patterns and regional variations in grip strength among older adults (50+) in India: evidence from WHO's Study on Global Ageing and Adult Health (SAGE). Archives of gerontology and geriatrics. 2018 May 1;76:100-5.

66. Bond J, Dickinson HO, Matthews F, Jagger C, Brayne C, CFAS M. Self-rated health status as a predictor of death, functional and cognitive impairment: a longitudinal cohort study. European Journal of Ageing. 2006 Dec 1;3(4):193-206.

67. Idler EL, Benyamini Y. Self-rated health and mortality: a review of twenty-seven community studies. Journal of health and social behavior. 1997 Mar 1:21-37.

68. Mograbi DC, de Assis Faria C, Fichman HC, Paradela EM, Lourenço RA. Relationship between activities of daily living and cognitive ability in a sample of older adults with heterogeneous educational level. Annals of Indian Academy of Neurology. 2014 Jan;17(1):71.

69. Cheval B, Boisgontier MP, Orsholits D, Sieber S, Guessous I, Gabriel R, Stringhini S, Blane D, van der Linden BW, Kliegel M, Burton-Jeangros C. Association of early-and adult-life socioeconomic circumstances with muscle strength in older age. Age and Ageing. 2018 May 1;47(3):398-407.

70. Van der Linden BW, Cheval B, Sieber S, Orsholits D, Guessous I, Stringhini S, Gabriel R, Aartsen M, Blane D, Courvoisier D, Burton-Jeangros C. Life course socioeconomic conditions and frailty at older ages. The Journals of Gerontology: Series B. 2020 Jun 2;75(6):1348-57.

71. Cheval B, Chabert C, Orsholits D, Sieber S, Guessous I, Blane D, Kliegel M, Janssens JP, BurtonJeangros C, Pison C, Courvoisier DS. Disadvantaged early-life socioeconomic circumstances are associated with low respiratory function in older age. The Journals of Gerontology: Series A. 2019 Jun 18;74(7):1134-40. 
72. Case A, Paxson C. Mothers and others: who invests in children's health?. Journal of health economics. 2001 May 1;20(3):301-28.

73. Umeda M, Oshio T, Fujii M. The impact of the experience of childhood poverty on adult health-risk behaviors in Japan: a mediation analysis. International journal for equity in health. $2015 \mathrm{Dec}$ 1;14(1):145.

74. Fernihough A, McGovern ME. Physical stature decline and the health status of the elderly population in England. Economics \& Human Biology. 2015 Jan 1;16:30-44.

75. Jain U, Ma M. Height shrinkage, health and mortality among older adults: Evidence from Indonesia. Economics \& Human Biology. 2020 May 1;37:100863.

\section{Tables}

Table 1 characteristics of the study population, WHO-SAGE Wave 1 (2007/10) 


\begin{tabular}{|c|c|c|c|}
\hline Background Characteristics & Categories & India & China \\
\hline Mean age (years, SD) & & $61.5(8.89)$ & $62.6(8.96)$ \\
\hline Mean height $(\mathrm{cm}, \mathrm{SD})$ & & 156.7(9.97) & $159.2(8.68)$ \\
\hline \multirow[t]{2}{*}{ Mean cognitive functioning (score, SD) } & & $38.1(10.01)$ & $50.9(11.8)$ \\
\hline & & $\%$ & $\%$ \\
\hline \multirow[t]{2}{*}{ Sex } & Male & 51 & 49.8 \\
\hline & Female & 49 & 50.2 \\
\hline \multirow[t]{2}{*}{ Residence } & Urban & 28.9 & 47.4 \\
\hline & Rural & 71.1 & 52.6 \\
\hline \multirow[t]{2}{*}{ Marital status } & Married & 76.9 & 85.1 \\
\hline & Otherwise & 23.1 & 14.9 \\
\hline \multirow[t]{4}{*}{ Schooling } & No formal education & 50.8 & 22.6 \\
\hline & Less than primary & 10.9 & 18.8 \\
\hline & Completed secondary & 24.4 & 40.9 \\
\hline & HS and above & 13.9 & 17.7 \\
\hline \multirow[t]{5}{*}{ Wealth Quintile } & Poorest & 18.2 & 16.3 \\
\hline & Poorer & 19.5 & 18.1 \\
\hline & Middle & 18.8 & 20.5 \\
\hline & Richer & 19.6 & 23.3 \\
\hline & Richest & 23.9 & 21.8 \\
\hline \multirow[t]{4}{*}{ Own employment } & Never worked & 27 & 8.6 \\
\hline & Informal employment & 22.2 & 2.6 \\
\hline & self-employed & 36.4 & 45.2 \\
\hline & Private/public sector & 14.4 & 43.6 \\
\hline \multirow[t]{4}{*}{ Mother's education } & No formal education & 90.2 & 87.4 \\
\hline & Less than primary & 5.3 & 6 \\
\hline & Completed secondary & 3.9 & 5.1 \\
\hline & HS and above & 0.6 & 1.5 \\
\hline Father's education & No formal education & 66.6 & 68.7 \\
\hline
\end{tabular}

Page 18/25 


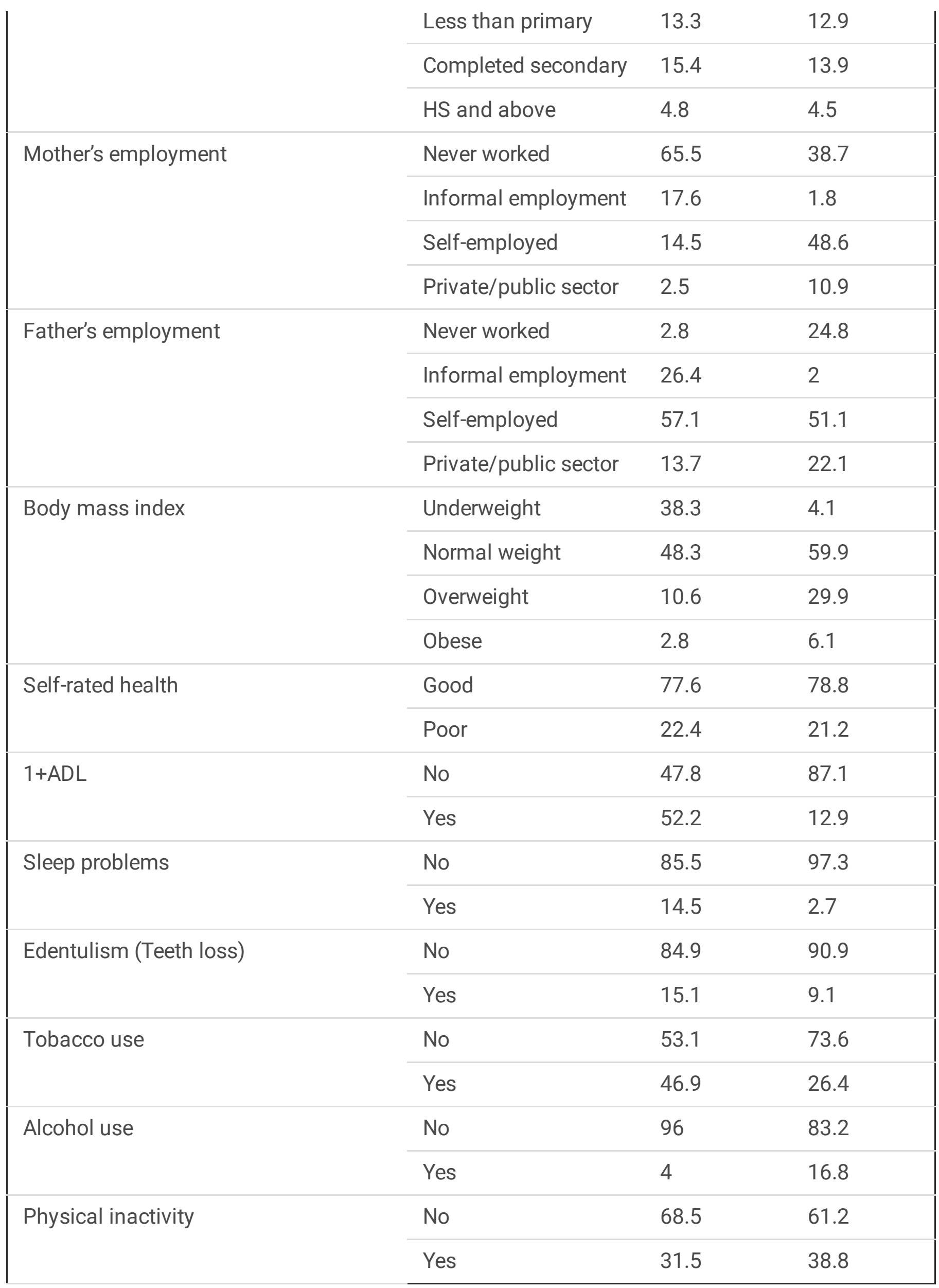


Table 2 Mixed effect linear regression results of cognitive functioning among older adults for India and China, WHO-SAGE Wave 1 (2007/10) 


\begin{tabular}{|c|c|c|c|}
\hline \multirow[t]{2}{*}{ Characteristics } & Categories & India & China \\
\hline & & $\beta(95 \% \mathrm{Cl})$ & $\beta(95 \% \mathrm{Cl})$ \\
\hline \multirow[t]{3}{*}{ Mother's education ${ }^{a}$} & Less than primary & $0.85 *(-.04,1.76)$ & $1.51^{\star \star \star}(.70,2.32)$ \\
\hline & Completed secondary & $1.55^{\star \star \star}(.42,2.68)$ & $0.98 * \star(.046,1.92)$ \\
\hline & HS and above & $3.06 * \star(.57,5.54)$ & $2.10 * \star(.48,3.73)$ \\
\hline \multirow[t]{3}{*}{ Father's education $^{a}$} & Less than primary & $0.79 \star \star(.17,1.42)$ & $1.35^{\star \star \star}(.76,1.93)$ \\
\hline & Completed secondary & $0.98 * \star *(.29,1.66)$ & $1.24^{\star \star \star}(.60,1.88)$ \\
\hline & HS and above & $2.53 * \star \star(1.37,3.70)$ & $3.55^{\star \star \star}(2.47,4.62)$ \\
\hline \multirow[t]{3}{*}{ Mother's employment ${ }^{\mathrm{b}}$} & Informal employment & $0.45(-.30,1.22)$ & $-0.15(-2.09,1.77)$ \\
\hline & Self-employed & $-0.27(-.93, .37)$ & $0.35(-.43,1.14)$ \\
\hline & Private/public sector & $-0.72(-2.06, .60)$ & $0.27(-.49,1.03)$ \\
\hline \multirow[t]{3}{*}{ Father's employment ${ }^{b}$} & Informal employment & $1.46 \star \star(.19,2.74)$ & $0.68(-1.07,2.45)$ \\
\hline & Self-employed & $2.31 \star \star \star(1.10,3.52)$ & $0.60(-.18,1.40)$ \\
\hline & Private/public sector & $2.22 * \star *(.90,3.54)$ & $0.37(-.34,1.08)$ \\
\hline \multirow[t]{4}{*}{ Height quintile ${ }^{c}$} & 2 & $0.82^{\star \star}(.19,1.45)$ & $0.95^{\star \star \star}(.39,1.52)$ \\
\hline & 3 & $1.04 * \star \star(.41,1.68)$ & $1.33^{\star \star \star}(.77,1.90)$ \\
\hline & 4 & $1.38 * * *(.74,2.02)$ & $1.63^{\star \star \star}(1.03,2.23)$ \\
\hline & Highest & $1.80 \star \star \star(1.14,2.45)$ & $2.23^{\star \star \star}(1.60,2.86)$ \\
\hline \multirow[t]{3}{*}{ Schooling ${ }^{a}$} & Less than primary & $3.80 \star \star \star(3.11,4.49)$ & $2.97 * \star \star(2.40,3.54)$ \\
\hline & Completed secondary & $5.64 * \star \star(5.04,6.24)$ & $5.45^{\star \star \star}(4.91,6.00)$ \\
\hline & HS and above & $9.28 \star \star \star(8.45,10.1)$ & $7.83^{\star \star \star}(7.10,8.57)$ \\
\hline \multirow[t]{4}{*}{ Wealth Quintile $^{d}$} & Poorer & $0.91 * * *(.22,1.60)$ & $0.77^{\star \star \star}(.20,1.35)$ \\
\hline & Middle & $1.42^{\star \star \star}(.71,2.13)$ & $1.05^{\star \star \star}(.43,1.67)$ \\
\hline & Richer & $2.01 * \star \star(1.28,2.74)$ & $2.29 \star \star \star(1.64,2.95)$ \\
\hline & Richest & $2.71 \star \star \star(1.94,3.49)$ & $2.09 * \star \star(1.35,2.82)$ \\
\hline \multirow[t]{3}{*}{ Own employment ${ }^{b}$} & informal employment & $0.59(-.12,1.32)$ & $1.22^{\star}(-.10,2.55)$ \\
\hline & Self-employed & $0.45(-.19,1.10)$ & $0.40(-.41,1.21)$ \\
\hline & Private/public sector & $1.25^{\star \star \star}(.48,2.02)$ & $2.46 * \star \star(1.68,3.25)$ \\
\hline Age (years) & & $-0.08^{\star \star \star \star}(-.11,-.05)$ & $-0.25^{\star \star \star}(-.28,-.23)$ \\
\hline
\end{tabular}




\begin{tabular}{|c|c|c|c|}
\hline \multicolumn{2}{|l|}{ Gender $^{\mathrm{e}}$} & $-2.92^{\star * \star}(-3.51,-2.34)$ & $-1.55^{\star \star \star}(-2.00,-1.09)$ \\
\hline \multicolumn{2}{|l|}{ Residence $^{f}$} & $-0.74 * *(-1.45,-.043)$ & $-0.71(-2.12, .69)$ \\
\hline \multicolumn{2}{|l|}{ Marital status ${ }^{g}$} & $-1.09 * \star *(-1.60,-.58)$ & $-0.83^{\star \star \star}(-1.34,-.32)$ \\
\hline \multirow[t]{3}{*}{ Body mass index ${ }^{h}$} & Underweight & $-0.85^{\star \star \star}(-1.30,-.39)$ & $-0.16(-1.05, .72)$ \\
\hline & Overweight & $0.91 * \star \star(.25,1.56)$ & $0.34 *(-.05, .74)$ \\
\hline & Obesity & $0.66(-.47,1.80)$ & $-0.11(-.90, .66)$ \\
\hline \multicolumn{2}{|l|}{ Sleep problems } & $-0.63 *(-1.28, .011)$ & $-1.12 *(-2.28, .045)$ \\
\hline \multicolumn{2}{|l|}{ Edentulism } & $-.66 * *(-1.26,-.064)$ & $-1.26 * \star *(-1.87,-.66)$ \\
\hline \multicolumn{2}{|l|}{ Poor self-rated health } & $-1.59 * \star \star(-2.15,-1.02)$ & $-2.05^{\star \star \star}(-2.52,-1.58)$ \\
\hline \multicolumn{2}{|l|}{$1+A D L$} & $-1.02^{\star \star \star}(-1.48,-.57)$ & $-2.80 * \star \star(-3.41,-2.20)$ \\
\hline \multicolumn{2}{|l|}{ Tobacco use } & $0.06(-.38, .51)$ & $0.07(-.43, .57)$ \\
\hline \multicolumn{2}{|l|}{ Alcohol use } & $-1.02 *(-2.05, .012)$ & $-0.30(-.85, .23)$ \\
\hline \multicolumn{2}{|l|}{ Physically inactive } & $-1.33^{\star \star \star}(-1.80,-.86)$ & $0.03(-.36, .43)$ \\
\hline \multicolumn{4}{|l|}{ Random part } \\
\hline \multicolumn{2}{|l|}{ Region } & $0.81(.39,1.67)$ & $1.49(.74,2.98)$ \\
\hline \multicolumn{2}{|l|}{ PSU } & $1.98(1.72,2.28)$ & $2.56(2.09,3.13)$ \\
\hline \multicolumn{2}{|l|}{ Individual } & $7.44(7.30,7.58)$ & $9.25(9.13,9.37)$ \\
\hline
\end{tabular}

${ }^{a}$ reference no education, ${ }^{b}$ reference never worked, ${ }^{c}$ reference lowest, ${ }^{d}$ reference poorest, ${ }^{e}$ reference male, ${ }^{f}$ reference urban, ${ }^{g}$ reference currently married, ${ }^{h}$ reference normal weight

$\mathrm{Cl}=$ confidence interval $* \star \star p<.001, * \star p<.005, * p<.01$

\section{Figures}


A. MOTHER'S EDUCATION-INDIA

\section{0}

44.0

$\sum_{\circlearrowright} \begin{aligned} & 42.0 \\ & 0\end{aligned} 3.0$

34.0

32.0

30.0

$\begin{array}{lllllll}50 & 55 & 60 & 65 & 70 & 75 & 80\end{array}$

AGE
B. FATHER'S EDUCATION-INDIA

46.0

44.0

42.0

40.0

38.0

36.0

34.0

32.0

30.0

$\begin{array}{lllllll}50 & 55 & 60 & 65 & 70 & 75 & 80\end{array}$

AGE
C. MOTHER'S EDUCATION-CHINA

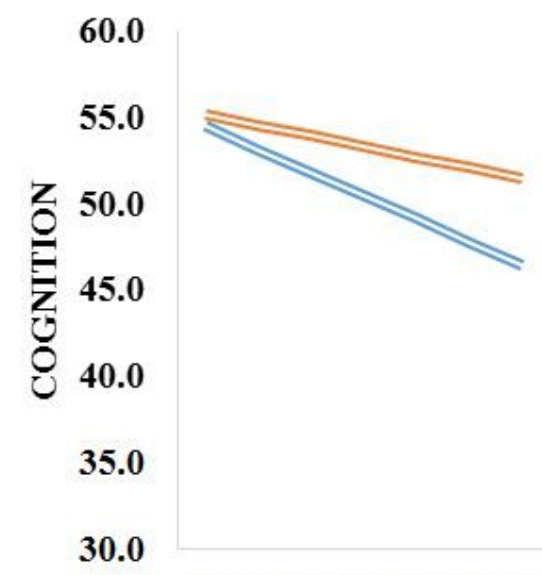

$\begin{array}{lllllll}50 & 55 & 60 & 65 & 70 & 75 & 80\end{array}$

AGE

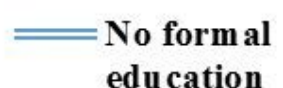
education

$=$ HS and above
D. FATHER'S EDUCATION-CHINA

60.0

55.0

50.0

45.0

40.0

35.0

30.0
No form al education

$=$ HS and above

$\begin{array}{lllllll}50 & 55 & 60 & 65 & 70 & 75 & 80\end{array}$

AGE

\section{Figure 1}

Predicted cognition score by parental education categories and age controlling socio-demographic, and health variables for India and China, WHO-SAGE Wave 1. A and B. Age pattern of cognition score of the study participants by mother's and father's education categories in India. Fig.1 C and D. Age pattern of cognition score of the study participants by mother's and father's education categories in China. 


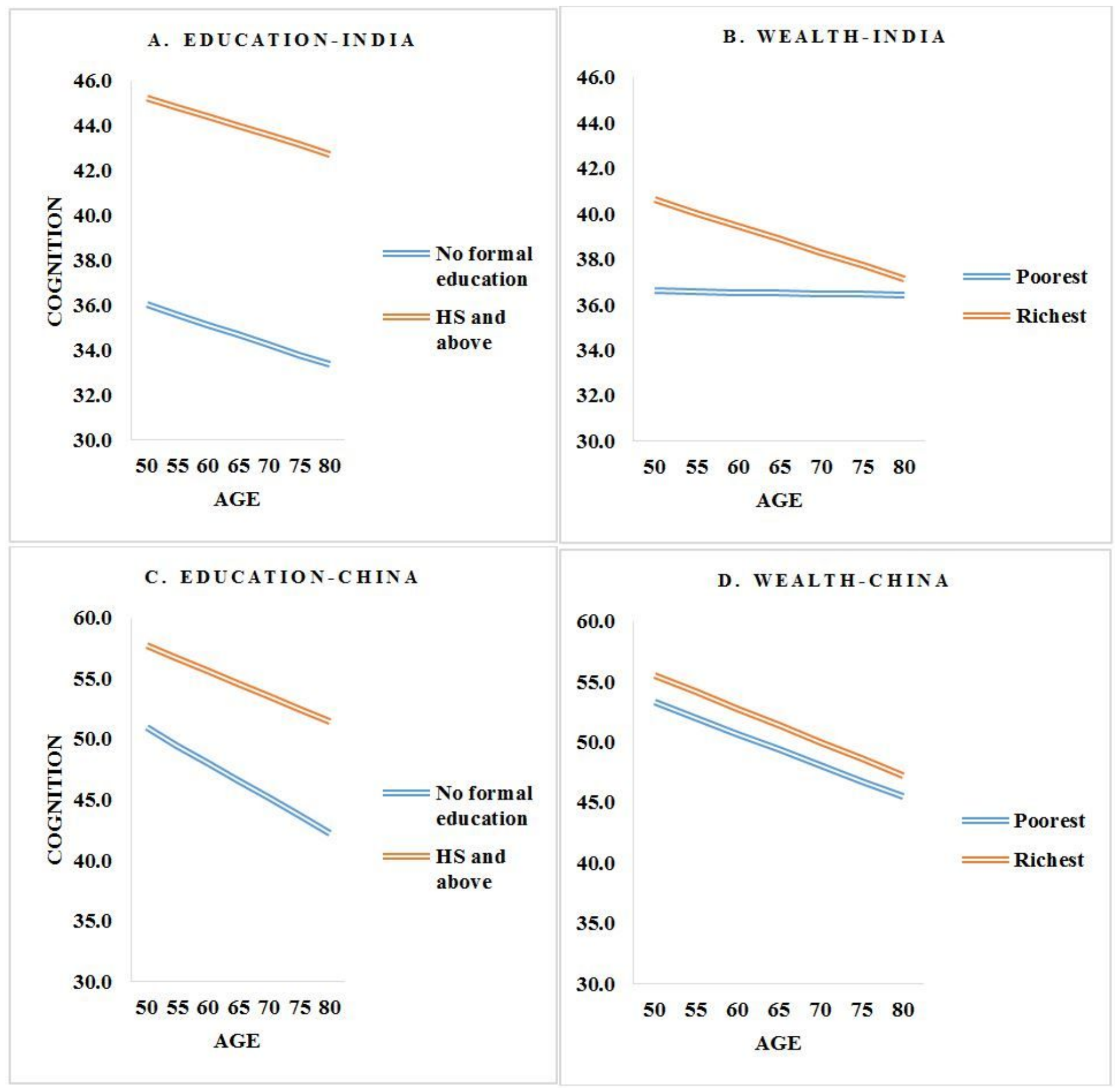

Figure 2

Predicted cognition score by years of schooling (study participants) and wealth quintile in relation to age controlling demographic, and health variables for India and China, WHO-SAGE Wave 1. A and B. Age pattern of cognition score by participant's education and wealth quintile categories in India. Fig. $2 \mathrm{C}$ and D. Age pattern of cognition score by participant's education and wealth quintile categories in China.

\section{Supplementary Files}


This is a list of supplementary files associated with this preprint. Click to download.

- Supplementary.docx 